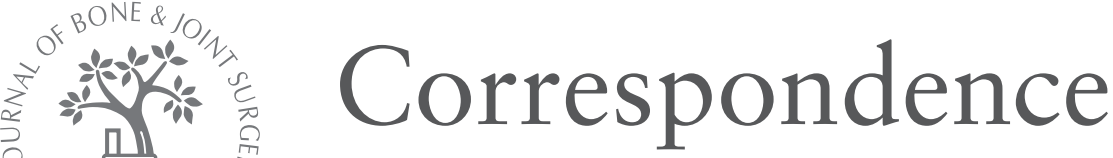

(c)2005 British Editorial Society of Bone and Joint Surgery \$2.00 J Bone Joint Surg [Br] 2005;87-B:1584-5.

\section{The complications of displaced intracapsular fractures of the hip}

Sir,

I read with great interest the article by Gurusamy, Parker and Rowlands ${ }^{1}$ in the May 2005 issue entitled 'The complications of displaced intracapsular fractures of the hip'.

In this study, the only factor the authors considered for cases of nonunion was the position of cannulated screws on radiographs. The rate of nonunion was approximately $39 \%$ in this series. However, it is well established that a number of other factors are also responsible for nonunion, for example comminution at the fracture site, osteoporosis, physiological age of the patient, apex-tip distance of screws, and delay between fracture and fixation. ${ }^{2}$ None of these factors was considered in this study.

The authors stated that they felt that mechanical failure of fixation should be blamed for most nonunions, which is a generalisation. In fact, in most cases of nonunion implant failure is secondary to biological failure.

Their other conclusion is that the degree of angulation between the screws had no measurable effect on the risk of nonunion. It is well known that collapse at the fracture site will not occur unless the screws are parallel. ${ }^{3,4}$ Lack of parallelism between the screws was one of the important factors in the failure of Gardens screws placed at $90^{\circ}$ used for fixation of these fractures. ${ }^{5}$

doi:10.1302/0301-620X.87B11.17089

M. TODKAR

Nuffield Orthopaedic Centre,

Oxford, UK.

1. Gurusamy K, Parker MJ, Rowlands TK. The complications of displaced intracapsular fractures of the hip. J Bone Joint Surg [Br] 2005;87-B:632-4.

2. Parker MJ. Prediction of fracture union after internal fixation of intracapsular femoral neck fractures: related articles. Injury 1994;25 (Suppl 2):3-6

3. Rehnberg L, Olerud C. Fixation of femoral neck fractures: comparison of Uppsala and Von Bahr screws. Acta Orthop Scand 1989;60:579-84.

4. Lagerby M, Asplund S, Ringqvist I. Cannulated screws for fixation of femoral neck fractures: no difference between Uppsala and Richards screws in a randomized prospective study of 268 cases. Acta Orthop Scand 1998:69:387-91.

5. Parker MJ, Porter KM, Eastwood DM, Schembi Wismayer M, Bernard AA Intracapsular fractures of the neck of femur: parallel or crossed garden screws? J Bone Joint Surg [Br] 1991;73-B:826-7.

Authors' reply:

Sir,

We thank Mr Todkar for his interest in our article. Indeed, there are numerous factors which influence the risk of fracture-healing complications for intracapsular fractures. Some of these factors may, however, only be associated with complications of healing, rather than being causal. A study of all these factors would be extremely difficult to undertake. The study by Barnes et $\mathrm{al}^{1}$ addressed some of these factors, but 23 pages of The Journal of Bone and Joint Surgery $[\mathrm{Br}]$ were required to report the findings.

The reader should not use the figures from our article to calculate the incidence of nonunion for displaced intracapsular fractures $(39 \%)$. As stated in our article, this is not a consecutive series of patients. Overall, 591 patients were treated at our unit for a non-pathological displaced intracapsular fracture during the period of the study. This gives a rate of nonunion of $26 \%$.

Regarding the parallel insertion of screws, one should differentiate between the methods previously described such as crossed Garden screws, in which there was an attempt to prevent fracture collapse by placing the screws at an angle of $60^{\circ}$ to $90^{\circ}$, and our study where the mean angle between the screws was $5^{\circ}$. We feel that a minor degree of angulation for screws in the osteoporotic bone of the femoral neck would not have much effect in preventing collapse of the fracture. As our study shows, the separation of screws into different areas of the bone is more effective in reducing the risk of nonunion than is parallelism.

doi:10.1302/0301-620X.87B11.17090

\section{PARKER, MD, FRCS}

T. ROWLANDS, MBBCh, MRCS (Eng)

Peterborough District Hospital,

Peterborough, UK.

K. GURUSAMY, MBBS, MRCS Ed

QUQM Hospital,

Margate, UK.

1. Barnes R, Brown JT, Garden RS, Nicoll EA. Subcapital fractures of the femur: a prospective review. J Bone Joint Surg [Br] 1976;58-B:2-24.

\section{Glove perforation and contamination in primary total hip arthroplasty}

Sir,

We read with great interest the article in the April 2005 issue by Al-Maiyah et $\mathrm{al}^{1}$ entitled 'Glove perforation and contamination in primary total hip arthroplasty'. It is interesting to note that changing gloves at regular intervals decreases the incidence of glove perforation and glove contamination during total hip arthroplasty. However, the authors did not mention the association between glove perforation and glove contamination in their study, which is an important issue to consider, with the data available to them.

Perforation of gloves can spread the bacterial flora from the skin to the surface of the gloves. But with $63 \%$ of the operations showing bacterial contamination in the operating field even under laminar air flow, ${ }^{2}$ contamination of the gloves can arise from anywhere in the field including being airborne. McCue, Berg and Saunders ${ }^{3}$ found draping to be an important factor in causing the contamination of outer gloves. Interestingly, Dodds et $\mathrm{al}^{4}$ showed 
that glove perforation did not influence the bacterial counts on the outer surface of the gloves in general surgical operations.

If perforation of the outer glove is associated with its contamination, it may indicate a causal relationship, suggesting that the inner gloves are one of the sources of contamination. In such circumstances, changing both the outer and inner gloves at regular intervals may be necessary to further reduce the incidence of contamination.

The association between perforation and contamination of the glove needs to be analysed from the data included in the authors' study. Determining the incidence of the perforation of inner gloves and their contamination as well could have further enhanced the outcome of their study.

doi:10.1302/0301-620X.87B11.16894

K. R. BODDU SIVA RAMA

S. APSINGI

Imperial College,

London, UK.

1. Al-Maiyah M, Bajwa A, Finn P, et al. Glove perforation and contamination in primary total hip arthroplasty. J Bone Joint Surg [Br] 2005;87-B:556-9.

2. Davis N, Curry A, Gambhir AK, et al. Intraoperative bacterial contamination in operations for joint replacement. J Bone Joint Surg [Br] 1999;81-B:886-9.

3. McCue SF, Berg EW, Saunders EAJ. Efficacy of double-gloving as a barrier to microbial contamination during total joint arthroplasty. J Bone Joint Surg [Am] 1981;63-A:811-13

4. Dodds RD, Guy PJ, Peacock AM, et al. Surgical glove perforation. Br J Surg 1988;75:966-8.

\section{Author's reply:}

Sir,

I thank Messrs Boddu Siva Rama and Apsingi for the interest they have shown in our article. We analysed the association between glove perforation and glove contamination from the available data. We found that there was poor correlation between glove perforation and glove contamination (Pearson correlation coefficient, $\mathrm{rp}=0.17, \mathrm{p}=0.24)$. Similar results were reached by Dodds et al. ${ }^{1}$ However, it is worth mentioning that single gloves were used in their study compared with double gloves in ours.

In our study the outer gloves were analysed for perforation and contamination. We, therefore, cannot comment upon the rate of inner-glove perforation and contamination.

doi:10.1302/0301-620X.87B11.16895

M. AL-MAIYAH, FRCS

James Cook University Hospital,

Middlesbrough, UK.

1. Dodds RD, Guy PJ, Peacock AM, et al. Surgical glove perforation. Br J Surg 1988:75:966-8.

\section{Glove perforation and contamination in primary total hip arthroplasty}

Sir,

We read with interest the article in the April 2005 issue by AlMaiyah et $\mathrm{al}^{1}$ entitled 'Glove perforation and contamination in primary total hip arthroplasty’.
There are many variables in this study which, if eliminated, would provide more conclusive evidence of the effectiveness of the technique. The criterion for a 20-minute glove change in this study for surgery of an average duration of 70 minutes seemed arbitrary and with no justification. As the surgeon and his team were unblinded they may have become biased, working more attentively and carefully in the study group, resulting in fewer glove perforations and contaminations.

Furthermore, upon analysing the results of Table I we note that the surgeon for each operation in the study group changed gloves only once more on average compared with the control group $((120-94$ pairs $) / 25$ operations $=1.04)$. The fact that this extra change of gloves per member of the surgical team in a single operation produces such a difference in the incidence of glove perforations and contaminations somehow appears unlikely.

doi:10.1302/0301-620X.87B11.16977

\section{A. AGARWAL, MS \\ R. AGARWAL, MD \\ Delhi, India.}

1. Al-Maiyah M, Bajwa A, Finn P, et al. Glove perforation and contamination in primary total hip arthroplasty. J Bone Joint Surg [Br] 2005;87-B:556-9.

\section{Author's reply:}

Sir,

We would like to thank Doctors Agarwal for their interest in our article. The choice of 20-minute intervals in this study group was not arbitrary. It followed careful observation of our practice and the evaluation of the results of our pilot study.

Surgical teams involved in the study used the same techniques and protocol. However, because of the nature of the study, whereby a surgeon has to change gloves, there is no objective scientific method to rule out the possibility of bias completely. It is unlikely that experienced arthroplasty surgeons would work less carefully in the control group.

In the study and control groups median operating times at 70 minutes (95\% confidence interval (CI) 60 to 80 ) and 75 minutes (95\% CI 65 to 90 ) respectively were similar. This shows that half the total number of operations lasted longer than the median time. In the study group no glove was used for longer than 20 minutes, while in the control group the gloves were worn for a longer time. Median times between each glove change were 16 minutes $(95 \%$ CI 15 to 20$)$ in the study group and 23 minutes (95\% CI 21.5 to 25$)$ in the control group. In those study group operations which lasted longer there was more than one glove change. However, in the controls there was a smaller number of gloves used even if the operation lasted longer than the median time, unless a perforation was noticed. We noticed more glove perforations in this group.

doi:10.1302/0301-620X.87B11.16978

\section{AL-MAIYAH, FRCS}

James Cook University Hospital, Middlesbrough, UK. 